\title{
A MORTE MEDIANTE AS REPRESENTAÇÕES SOCIAIS DOS PROFISSIONAIS DE SAÚDE
}

\author{
DEATH ACCORDING TO THE SOCIAL REPRESENTATIONS OF HEALTH \\ PROFESSIONALS
}

\section{LA MUERTE MEDIANTE LAS REPRESENTACIONES SOCIALES DE LOS PROFESIONALES DE LA SALUD}

\author{
Maria das Dores Vale Oba ${ }^{1}$ \\ Maria Solange Guarino Tavares ${ }^{2}$ \\ Maria Helena Pessini de Oliveira ${ }^{3}$
}

\begin{abstract}
RESUMO: Objetivo desta investigação foi conhecer e analisar a morte mediante as representações sociais dos profissionais de saúde que prestam atendimento à mulher no periodo gravídico-puerperal. Optou-se pela análise de conteúdo, mas também foi ancorada nas representações sociais. Através das falas destes emergiu a categoria empírica nas representações sociais da morte denominada de "terrivel". Ao entrar em cena, no ambiente hospitalar ou ambulatorial, a morte será apreendida de diferentes formas pelos profissionais de saúde: uma fase da vida, terrivel, dificil de ser aceita, conflito sobre a finalidade de sua profissão, procura alguma falha no procedimento realizado que a justifique e nesse momento vivenciam os sentimentos de insegurança, incapacidade, constrangimento, culpa, angústia, sofrimento e dor.
\end{abstract}

PALAVRAS-CHAVE: enfermagem obstétrica, morte, saúde da mulher

ABSTRACT: The purpose of this investigation was to acknowledge and to analyze death according to the social representation of health professionals. The research was carried out with professionals that renders assistance to the women in the gestation-puerperal period. The technique of content analysis was chosen, but data analysis was also anchored in social representations. From the narratives of the subjects interviewed, death emerged as an empirical category with a social representation denominated as "terrible". Death, as it enters the scene, both in hospital or ambulatory settings, is apprehended in different ways by health professionals: as a terrible phase of life that is difficult to be accepted, as a conflict over the purpose of one's profession, as a way of seeking for mistakes in the procedure carried out in order to justify it, and, at this moment, professionals experience feelings of insecurity, incapacity, embarrassment, guilt, anguish, suffering and pain.

KEYWORDS: obstetric nursing, death, women's health

RESUMEN: El objetivo de esta investigación ha sido conocer y analizar la muerte mediante las representaciones sociales de los profesionales de la salud. La investigación se llevó a cabo con profesionales que prestan atención a la mujer en el periodo gravídico-puerperal. Se optó por el análisis de contenido, pero también está anclado en las representaciones sociales. A través de los discursos ha emergido la categoria empírica en las representaciones sociales de la muerte, denominada de "terrible". Al entrar en escena, en el ambiente del hospital o ambulatorial, la muerte será aprehendida de diferentes formas por los profesionales de la salud: una fase de la vida, terrible, dificil de aceptarse, generadora de conflictos sobre la finalidad de su profesión, o búsqueda de alguna falla en el procedimiento realizado que la justifique y a partir de todo ello los profesionales pasan a vivir los sentimientos de inseguridad, incapacidad, vergüenza, culpa, angustia, sufrimiento y dolor.

PALABRAS CLAVE : enfermeria obstétrica, muerte, salud de la mujer

Recebido em 21/05/2001

Aprovado em 06/02/2002

\footnotetext{
${ }^{1}$ Doutora em Enfermagem. Mestre em Enfermagem em Saúde Pública. Enfermeira da Secretaria Municipal de Saúde - Ribeirão Preto.

2 Doutora em Enfermagem. Orientadora do Programa de Doutoramento em Enfermagem do Interunidades da EE e EERP, USP. Coordenadora do Curso de Enfermagem UNIBAN-RP/USP.

${ }^{3}$ Professora. Doutora em Enfermagem. Orientadora e Coordenadora do Curso de Enfermagem da UNAERP Ribeirão Preto.
} 


\section{INTRODUÇÃO}

O século $X X$ traz a morte que se esconde, a morte vergonhosa, a morte que não pertence mais à pessoa, tira-se a sua responsabilidade e depois a sua consciência. A sociedade atual expulsou a morte para proteger a vida. Não há mais sinais de que uma morte ocorreu. O grande valor do século atual é o de dar a impressão de que "nada mudou", a morte não deve ser percebida (KOVÁCS, 1992).

A morte acabou por ser banida, ocultada, proibida das preocupações do homem ocidental neste século. Ora, ao ocultar a morte o homem atinge a própria vida (MARCÍLIO,1983).

A vida é assim, ligada à morte pelo umbigo, vida e morte juntas e opostas. Ao se falar da vida, não se pode deixar de falar da morte, porque são uma coisa só.....A vida natural ocorre entre o nascimento e a morte no tempo certo. O rompimento desse ciclo natural representa um perigo não só para aquele que deixa de cumprilo, mas também para toda sociedade (MARTINS, 1983, p. 259).

Na sociedade ocidental não há igualdade diante da morte, de acordo com as condições sociais, econômicas e políticas ela poderá se adiantar ou se atrasar e, da mesma forma, a indústria funerária imporá seus valores às pompas fúnebres, o valor do terreno para o sepultamento, a localização no cemitério, as taxas municipais, etc.

A sociedade mercantil cria um sistema de imortalidade das pessoas, negando qualquer status aos mortos, e carrega o momento da morte de todas as qualificações pejorativas, que se possa imaginar, esvazia, oculta, nega a morte. É um sistema que aliena a quem morre, privandoo de sua própria morte. Mesmo com todo o poder na mão do médico e o paciente sem nenhum, ele continua sendo o sujeito epistêmico de sua morte (KOVÁCS, 1992, p. 41).

A morte está presente no cotidiano da sociedade moderna como uma assombração que deve ser evitada. Os mortos, os velhos e os doentes são despachados para seus devidos lugares, isto é, aos cemitérios, asilos e hospitais, e são tratados como se fossem contaminados pela morte. Nessa sociedade de consumo, o trabalho, a compra e o lazer são elementos-chave e quem não participa desse circuito sofre uma morte social (KAMAL, 1983).

A sociedade industrial não tem lugar para os mortos: são seres que não produzem, não consomem, não respondem. Aos seus condicionantes: não competem, não correm, não ligam para o tempo, nem para o dinheiro. Os mortos são marginais do sistema ao nos lembrar que, por mais que nos empenhemos no processo competitivo de luta para ter, possuir, vencer, um dia seremos um marginal, um despojado. Não há como não encarar nossa projeção nesse " não ter". Só há que negá-los (SANTOS, 1983, p. 23).

Nos centros urbanos brasileiros das regiões mais desenvolvidas observa-se uma mudança nos ritos funerários, passam do espaço privado para o público e nesse novo espaço sofrem a exploração capitalista da morte que especula o aparato desse ritual. A morte é concebida em um silêncio civilizado, que imprime atitudes racionais, práticas e remove rapidamente o moribundo da vida dessa sociedade.

O local da morte, na sociedade capitalista ocidental é transferido do lar para o hospital. No século $X X$, a maioria das pessoas não vê os parentes morrerem. O hospital é conveniente, pois esconde a repugnância e os aspectos sórdidos ligados à doença. A familia também fica afastada para não incomodar o silêncio dos hospitais. Desse modo, não atrapalha o trabalho dos médicos e não torna visivel a presença da morte através de lamentações, choros ou questionamentos (KOVÁCS, 1992).

Assim nesta pesquisa tem-se por objetivo:

Conhecer e analisar as representações sociais dos profissionais de saúde de uma Unidade Básica Distrital de Saúde da região norte e de um Hospital Filantrópico da região central do municipio de Ribeirão Preto-SP sobre a morte.

\section{METODOLOGIA}

Os dados deste estudo fazem parte da tese de Doutorado: "A morte materna mediante as representações sociais dos profissionais de saúde no municipio de Ribeirão Preto-SP" que foi apreciado pela comissão de ética em pesquisa da Escola de Enfermagem de Ribeirão Preto da Universidade de São Paulo, sendo realizado no mês de julho de 1999, em uma Unidade Básica Distrital de Saúde da região norte e no Hospital Filantrópico da região central do município de Ribeirão Preto-S.P. Como também na Coordenação do Programa de Assistência a Saúde da Mulher e no Comitê de Estudo e Prevenção de Morte Materna.

A Unidade Básica Distrital de Saúde da região norte localiza-se em uma área de grandes bolsões de miséria, que realiza atendimento nas áreas básicas programáticas (gineco-obstetrícia, clínicamédica, odontológico e enfermagem), especialidades e pronto atendimento, com um horário de atendimento de 24 horas. Sendo que $65 \%$ dos profissionais de saúde desenvolvem suas atividades no pronto atendimento.

O Hospital Filantrópico da região central é uma instituição considerada de referência secundária e/ou terciária no sistema de saúde municipal de Ribeirão 
Preto de outros municipios e Estados. Foi criado em 1896, com intuito de atender pacientes sem condições de pagar, sem fins lucrativos e não recebia subsídios do Estado e seu faturamento era através de atendimento a pacientes de convênios (SUS e outros), das doações e da administração dos imóveis pertencentes a o mesmo (RIBEIRÃO PRETO, 1996).

Buscando atingir o objetivo proposto nesta pesquisa utiliza-se abordagem qualitativa, uma vez que essa nos induz a aprofundar na abordagem social da saúde. Pode-se dizer que há uma ordem de significados culturais mais abrangentes, que informa o olhar lançado sobre o corpo que adoece e morre (MINAYO,1994). Optou-se pela análise de conteúdo, segundo Bardin (1979).

Esta pesquisa também foi ancorada nas representações sociais. Entende-se aqui representações sociais, enquanto linguagem do senso comum, que se manifestam em condutas e chegam a ser institucionalizadas. Portanto, podem e devem ser analisadas a partir da compreensão das estruturas e dos comportamentos sociais (MINAYO,1994).

Elegeu-se a entrevista semi-estruturada e a observação livre como técnicas de coleta de dados.

A amostra foi constituida por profissionais de saúde, que atuam na assistência à saúde da mulher na Unidade Básica Distrital de Saúde Norte (dois médicos ginecologistas, três enfermeiras e dois auxiliares de enfermagem); na Coordenação do Programa de Assistência Integral a Saúde da Mulher da Secretaria Municipal de Saúde de Ribeirão PretoSP (um médico ginecologista); no Comitê de Estudo e Prevenção da Morte Materna (um médico ginecologista, membro do comitê e representante da Divisão Regional de Saúde de Ribeirão Preto-DIRXVIII); na assistência ambulatorial e hospitalar do processo de trabalho de parto no Hospital Filantrópico da região central(três médicos ginecologistas, duas enfermeiras, sendo uma do setor ambulatorial e outra da maternidade e três auxiliares de enfermagem, sendo uma do setor ambulatorial e duas da maternidade), totalizando dezessete sujeitos sociais.

Os sujeitos sociais que participaram desta investigação deram o seu consentimento livre e esclarecido. Como critério de inclusão optou-se pelo profissional de saúde que atuavam na assistência à saúde da mulher no momento da investigação, ou seja, no pré-natal, parto e puerpério, na Coordenação do Programa de Assistência Integral à Saúde da Mulher e no Comitê de Estudo e Prevenção da Morte Materna.

\section{RESULTADOS}

Nas falas dos sujeitos sociais em estudo emergiu a categoria empírica nas representações sociais da morte denominada de "terrivel". A morte tem sido apreendida e representada de diferentes maneiras pelos homens, de acordo com a tradição cultural, familiar e o contexto socioeconômico e, através desses parâmetros, terá qualidades, formas, personificações, ou seja, terá a sua própria representação social.

Percebe-se que os profissionais de saúde têm grande dificuldade em reconhecer os seus próprios limites. Assim, utilizam-se de mecanismos de defesa para negar um acontecimento natural e inevitável da vida, a morte! Nota-se essa dificuldade nas falas do sujeitos sociais em estudo.

Ao entrar em cena, no ambiente hospitalar ou ambulatorial, a morte será apreendida de diferentes formas pelos profissionais de saúde: uma fase da vida, terrivel, dificil de ser aceita, conflito sobre a finalidade de sua profissão, procura alguma falha no procedimento realizado que a justifique e nesse momento vivenciam os sentimentos de insegurança, incapacidade, constrangimento, culpa, angústia, sofrimento e dor, como se observa na fala a seguir.

Olha é uma experiência muito difícil é a morte, a nossa finalidade, da nossa profissão é justamente o tempo todo evitar qualquer complicação, não digo nem a morte, qualquer complicação, é evitar o sofrimento e a dor da paciente...(Prof.2).

O traumatismo da morte é, em certa medida, toda a distância que separa a consciência da morte da aspiração à imortalidade, toda a contradição, que opõe o fato brutal da morte à afirmação da sobrevivência (MORIN, 1970) conforme se observa nessa fala.

É a gente é muito céptico, é muito vil, a gente acha que é treinado, para vivenciar tanto a vida, quanto a morte de uma maneira muito natural, né...eu acho, que a morte é terrivel, realmente choca todo mundo...(Prof.1)

Percebe-se um discurso institucional que, em nome do profissionalismo, estimula a impessoalidade e tenta distanciar quem trabalha dos principais fatos que configuram essa realidade, a dor, o sofrimento e a morte.

Para tanto, as instituições têm-se utilizado de mecanismos de defesa estruturados socialmente que aparecem como elementos na estrutura, na cultura e no modo de funcionamento da organização, de maneira a não interferir na dinâmica e na assistência prestada (MARTINS; ALVES; GODOY, 1999).

Os profissionais de saúde, no cotidiano dos serviços e na racionalidade de um processo de trabalho cujo enfoque é a produção e não o produto desse trabalho, exercitam relações impessoais, fragmentárias, o isolamento e a indiferença afetiva, conforme se observa na fala do sujeito social em 
estudo.

...mas a gente todo dia tá vendo isso, eu não sei se a gente se acostuma ou fica meio frio, né, mas eu acho que é uma coisa assim, que a gente tem que aprender, né, quem trabalha nessa área, apesar de que tem casos, que a gente fica bem emotivo (Prof.12).

A sociedade ocidental cultiva o caráter acidental da morte: acidentes, doenças, infecções, etc. A morte fica despojada do caráter de necessidade em termos do processo vital. É sempre um assombro. O traumatismo provocado pela morte é sempre uma irrupção no real. No inconsciente, estamos todos persuadidos da nossa imortalidade, sem registro da morte, como o animal cego (KOVÁCS, 1992).

Os homens, ao alienarem-se da morte, deixam de vivenciar os sentimentos, significados e a possivel determinação do caráter sociocultural e econômico que define o modo e as condições de morte, os sentimentos e as condições de vida, a exploração que destrói a memória de um povo.

A morte, porém, não afeta os profissionais de saúde do mesmo modo. A maneira como eles reagem varia, em geral, de acordo com a idade do morto, a circunstância em que ocorreu essa morte e grau de envolvimento com o paciente, conforme se observa na fala a seguir.

.. há uma sensibilidade maior, quando é uma criança, um RN uma criança em uma situação delicada, um acidente ou não resistiu após o parto, isso é mais sensível... (Prof.6).

Os profissionais de saúde expressam em suas falas que a morte é um processo natural do ciclo da vida, mas como sujeitos sociais banhados por uma cultura ocidental pela qual apreendem a morte como fim, ruptura, fracasso, vergonha e ocultação apresentam atitudes de ocultar a morte vivenciada, manifestam os sentimentos de culpa, vergonha, angústia, vazio, tristeza, etc, conforme se observa na fala do sujeito social em estudo.

A morte...eu considero uma fase normal, uma fase de vida, como você nasce, desenvolve e morre, porém, em algumas situações são mais sensíveis e outras já se há uma espera de que o organismo já está entrando em falência.... (Prof. 11).

Martins em seu livro (1983, p. 9) afirma que:

A concepção da morte revela a concepção da vida. Uma sociedade, para qual a morte já não tem sentido, é também uma sociedade,.... que perdeu o sentido da vida. Estamos vivendo esse momento, de perda, de falta de sentido. Já não sabemos mais o que é a morte, porque já não sabemos com clareza o que é a vida.

A apreensão das dimensões cultural e social da morte na sociedade ocidental capitalista permite compreender as transformações das relações sociais dos profissionais de saúde em relação aos seus sentimentos e significados diante da morte.

Embora o homem seja o único ser consciente de sua mortalidade e finitude, a sociedade capitalista, com toda a sua tecnologia, faz com que os homens fiquem inconscientes e privados de sua própria morte. O hospital é um microcosmos onde se resumem, com muita clareza, os conflitos constitutivos da sociedade ocidental, percebe-se que muitas vezes o paciente não sabe como morrer e o profissional da saúde é incapaz de lhe explicar o sentido da morte (KOVÁCS, 1992), conforme se observa nesta fala.

... a morte é uma coisa extremamente chocante, né, para todos nós, que não aprendemos a conviver com ela, não aceita o sofrimento, nossa sociedade é uma sociedade que não cultivamos a morte né, então a gente não a entende e não aceita essa idéia... (Prof.3).

Os profissionais de saúde, cuja formação científica trata os fenômenos da vida e da morte como eventos da esfera biológica e, como tais, podem ser desvendados e controlados. Dessa forma, não apreendem a morte e a vida como pertencendo também à esfera da natureza e cultura.

Assim, esses profissionais, através de seus saberes, buscam desvendar os segredos do corpo humano, conhecer o seu funcionamento, recuperar o seu equilibrio, abalado pela enfermidade, vencer a morte, ou, no mínimo, controlá-la, adiando-a, eis, pois, os grandes desafios que se vão colocando no exercício da prática profissional no setor da saúde (CONSORTE, 1983), conforme se observa na fala do sujeito social em estudo.

... Onde foi que a gente falhou? Onde? No que a gente errou? muitas vezes a gente não falhou nada, foi perfeito, e não tem como a gente evitar determinados acontecimentos, então é uma coisa, que angustia muito a gente, traz sofrimento e dor... (Prof.2).

Os profissionais de saúdevão apreendendo no seu dia-a-dia que a dor, o sofrimento não são apenas sinais/sintomas e a morte não se traduz em simplesmente a mais uma declaração de óbito.

Ao se aperceberem das suas condições humanas, vivenciam momentos nesse cotidiano de trabalho que os afetam e lhes provocam outros sentimentos como insegurança, incapacidade, constrangimento, impotência, sofrimento e dor, conforme se observa na fala a seguir.

É difícil para o médico como é difícil para a familia,... gera insegurança na gente, incapacidade, é, às vezes o constrangimento, o sentimento de culpa, que a gente poderia ter feito mais alguma coisa e a gente fica questionando o tempo todo... (Prof.9). 


\section{CONSIDERAÇÕES FINAIS}

Se a morte é apreendida pelos profissionais de saúde como fim, ruptura, fracasso, vergonha e ocultação, ao depararem-se com a morte, essa experiência passa a ser "terrivel" e mostra que os profissionais não são formados para compreender a morte enquanto um momento do ciclo da vida (OBA, 2000).

Dessa forma os profissionais de saúde passam por momentos de questionamento sobre a sua finalidade profissional (prática voltada para vida e recusa da morte), manifestam sentimentos de insegurança, incapacidade, constrangimento, angústia, sofrimento, dor, culpa e procuram alguma falha nos procedimentos que a justifique.

Ao analisar os conteúdos das entrevistas dos profissionais de saúde, percebe-se a importância de uma proposta educativa que venha prepará-los para essa experiência do seu cotidiano de trabalho e da vida e, assim, quem sabe, poderão apreender que a morte é um momento do ciclo da vida e, portanto, não é um desafio a ser vencido.

A morte está no universo físico-quimico, onde a vida se encontra constantemente ameaçada de recair, mas onde se formou, teceu e desenvolveu. A morte está na indeterminação microfísica, mas essa indeterminação encontra-se ao mesmo tempo na origem das mutações e das criações, de toda criação. A mutação, fonte da morte, é indistinta da fonte da vida (MORIN, 1970, p.325).

\section{REFERÊNCIAS BIBLIOGRÁFICAS}

BARDIN, L. Análise de conteúdo. Lisboa: Edições 70,1979 .

CONSORTE, J. A. morte na prática médica. In: MARTINS, J.S. A morte e os mortos na sociedade brasileira. São
Paulo: Hucitec, 1983. p.38-60.

KAMAL, T.A. A morte, o sobrenatural e a continuação da vida. In: MARTINS, J.S. A morte e os mortos na sociedade brasileira. São Paulo: Hucitec,1983. p.201210.

KOVÁCS, M.J. Morte e desenvolvimento humano. 2. ed. São Paulo: Casa do Psicólogo,1992.

MARCÍLIO, M.L. A morte de nossos ancestrais. In: MARTINS, J.S. A morte e os mortos na sociedade brasileira. São Paulo: Hucitec,1983. p.61-75.

MARTINS, J.S. A morte e os mortos na sociedade brasileira. São Paulo: Hucitec, 1983.

MARTINS, E.L.; ALVES, R. N.; GODOY, S. F. G. Reações e sentimentos do profissional de enfermagem diante da morte. Revista Brasileira de Enfermagem, Brasilia, v.52, n.1, p.105-117, jan./mar. 1999.

MINAYO, M. C. S. O desafio do conhecimento: pesquisa qualitativa em saúde. Rio de Janeiro: HucitecAbrasco,1994.

MORIN,E. O homem e a morte. 2. ed. Portugal: Publicações Europa-América,1970.

OBA, M.D.V. A morte materna mediante as representações sociais dos profissionais de saúde no município de Ribeirão Preto-SP. Ribeirão Preto, 2000. 222 f. Tese (Doutorado) - Programa Interunidades das Escola de Enfermagem e Escola de Enfermagem de Ribeirão Preto, USP.

RIBEIRÃO PRETO. Sociedade Beneficiente Santa Casa de Misericórdia de Ribeirão Preto. Santa Casa 100 anos (1896-1996). Ribeirão Preto: Souza \& Sá, 1996. p.1-27.

SANTOS,C.A.F Os profissionais de saúde enfrentamnegam a morte. In: MARTINS, J.S. A morte e os mortos na sociedade brasileira. São Paulo: Hucitec, 1983. p.1524. 